\title{
Neurological manifestations in chronic mountain sickness: the burning feet-burning hands syndrome
} P K Thomas, R H M King, S F Feng, J R Muddle, J M Workman, J Gamboa, R Tapia,
M Vargas, O Appenzeller

\begin{abstract}
Objective-To characterise the clinical features and nerve biopsy findings in patients with chronic mountain sickness (CMS) living in the Peruvian Andes, with particular attention to the occurrence of the "burning feet-burning hands" syndrome.
\end{abstract}

Methods-Symptoms and signs were documented clinically in 10 patients with CMS and compared with those in five healthy subjects all living at 4338 metres altitude. Sural nerve biopsies were obtained from three patients with CMS.The nerve fibre population and endoneurial microvessels were analyzed morphometrically.

University

Department of Clinical

Neurology, Institute of

Neurology, London

WC1N 3BG, UK

P K Thomas

University

Department of Clinical

Neurosciences, Royal

Free and University

College Medical

School, London, UK

R H M King

S F Feng

J R Muddle

J M Workman

Instituto de

Investigationes de

Altura, Universidad

Peruana Cayetano

Heredia, Lima, Peru

J Gamboa

M Vargas

Departmento de Ciencias Fisiologicas, Universidad Peruana Cayetano Heredia, Cerro de Pasco, Peru R Tapia

New Mexico Health Enhancement and Marathon Clinics

Research Foundation, Albuquerque, NM, USA

O Appenzeller

Correspondence to: Professor P K Thomas pkt.hotline@virgin.net

Received 1 December 1999 and in revised form

5 April 2000

Accepted 20 April 2000
Results-All patients with CMS experienced burning and tingling paraesthesiae in the distal parts of their limbs. Similar but milder symptoms confined to the feet occurred in four of five controls. Three patients with CMS had a mild sensory neuropathy on examination, controls were clinically normal. Nerve biopsies showed a mild demyelinating neuropathy in all three with a reduction in the unmyelinated axon population in one. The endoneurial blood vessels showed a reduced thickness in the basal laminal zone compared with control values but were other-

Conclusions-Apart from well recognised symptoms and signs of CMS, the study has shown that such patients may also exhibit a mild sensory neuropathy. Its relation to the burning feet-burning hands syndrome, which was not confined to the patients but was also found in controls at altitude, is uncertain. The time course and pattern of the centrifugal resolution of the burning paraesthesiae complex on low altitude sojourn of high altitude natives raises the possibility that a mechanism involving altered axonal transport may be involved. The reduced thickness of the basal laminal zone of microvessels implies that adaptive structural changes to hypobaric hypoxia may also occur in peripheral nerve and are similar to those reported in other tissues of high altitude natives.

(F Neurol Neurosurg Psychiatry 2000;69:447-452)

Keywords: peripheral neuropathy, burning feet-burning hands syndrome; chronic mountain sickness; hypoxia wise normal.
Chronic mountain sickness (CMS) is a maladaptation syndrome to chronic hypoxaemia in Andean natives who consistently live at high altitude. ${ }^{12}$ It was first described by Monge ${ }^{3}$ in 1925 in Andean Indians in Peru. This condition usually affects men between the ages of 20 and 50 years and is very common in miners living in Cerro de Pasco, Peru, at an altitude of 4338 metres. ${ }^{4}$ The salient symptoms are malaise, depression, headaches of migrainous type, ${ }^{5}$ "dizziness", easy fatiguability, paraesthesiae, cognitive difficulty, somnolence and, rarely, episodes of coma. It is accompanied by cyanosis; suffused conjunctivae, cheeks, and ear lobes; peripheral oedema; clubbing of the fingers and toes; and splinter haemorrhages. Congestive cardiac failure may develop, with enlargement of the right side of the heart radiologically and ECG evidence of right heart hypertrophy.

Polycythaemia is present which is inappropriately high for the altitude, with packed cell volume values usually running at greater than $64 \%$. Total red cell mass is increased with haemoglobin values greater than $21.3 \mathrm{mg} / \mathrm{dl}{ }^{6}$ Oxygen saturation is reduced, with $\mathrm{SaO}_{2}$ values of around $70 \%$ or less. Hyperventilation, which usually maintains $\mathrm{PO}_{2}$ concentrations at around $50 \mathrm{~mm} \mathrm{Hg}$ at high altitude in normal people, does not occur in the patients, this being related to a failure of the respiratory centres to respond to $\mathrm{CO}_{2}$ stimulation. The ventilatory response to hypoxia is almost absent. ${ }^{7}$ Respiratory drive is thus lost and hypoventilation occurs. It is not established whether the cause lies with the peripheral chemoreceptors or with the brainstem regulatory mechanisms. Respiration is disordered during sleep, with episodic hypopnoea and apnoea. ${ }^{89}$

It came to our notice that subjects living at high altitude experience troublesome burning pain distally in the limbs. ${ }^{4}$ This present study records clinical and nerve biopsy findings on a series of patients with this symptom who were investigated in Cerro de Pasco, Peru, in September 1997. A report on some of the findings has appeared in abstract form. ${ }^{10}$

\section{Methods}

PATIENTS

Observations were made on 10 native South American patients with symptomatic CMS living in Cerro de Pasco, Peru (six men, four women; age range $58-72$ years). They were not selected on the basis of the occurrence of sensory symptoms. None of the patients were miners, exhibited chest deformity, or had evidence of chronic respiratory disease, and 
none had conditions known to cause peripheral neuropathy such as diabetes mellitus. One patient was not included because of a history of high alcohol intake. The 10 patients with CMS were compared with five healthy volunteer control subjects from the same locality without features of CMS. The mean packed cell volume for the patients with CMS was $69 \%$ (range $60-78 \%$ ) and that for the control subjects was $55 \%$ (range $49-60 \%$ ). These values were significantly different $(p<0.005)$.

NERVE BIOPSY

Sural nerve biopsy (full thickness) from a standard site posterior to the lateral malleolus was undertaken, with informed consent, from three patients aged 30, 52, and 64 years (one man, two women) under local anaesthesia. All three had evidence on examination of a mild peripheral neuropathy (see later). The specimens were fixed in $2.5 \%$ glutaraldehyde in piperazine- $N$ $N$ '-bis (2-ethane sulphonic acid) (PIPES)) buffer $^{11}$ and despatched by courier to London. Previous experience in our laboratory has shown that this does not introduce significant artefact. After postosmication and dehydration, part of the specimen was embedded in Durcupan. Semithin sections were stained with thionin and acridine orange. ${ }^{12}$ Ultrathin sections were contrasted with methanolic uranyl acetate and lead citrate and examined in a Zeiss EM902 electron

Table 1 Clinical features

\begin{tabular}{lcl}
\hline & $\begin{array}{l}\text { CMS } \\
(n=10)\end{array}$ & $\begin{array}{l}\text { Controls } \\
(n=5)\end{array}$ \\
\hline Symptoms: & 10 & 1 \\
$\quad$ Headaches & 5 & 0 \\
$\quad$ "Dizziness" & & \\
$\quad$ Burning/tingling paraesthesiae: & 10 & 4 \\
$\quad$ Feet & 9 & 0 \\
$\quad$ Hands & 0 & 0 \\
$\quad$ Ataxia & 0 & 0 \\
Neurological signs: & 3 & 0 \\
$\quad$ Motor & & \\
$\quad$ Reflex loss/depression & 0 & 0 \\
$\quad$ Distal sensory impairment: & 3 & 0 \\
$\quad$ Upper limbs & 2 & 0 \\
$\quad$ Lower limbs & & \\
Ataxia & & \\
\hline
\end{tabular}

CMS $=$ chronic mountain sickness.

Table 2 Sural nerve morphometry

\begin{tabular}{lcl}
\hline Case (sex/age) & $\begin{array}{l}\text { Myelinated fibre } \\
\text { density }\left(\mathrm{mm}^{-2}\right)\end{array}$ & $\begin{array}{l}\text { Unmyelinated axon } \\
\text { density }\left(\mathrm{mm}^{-2}\right)\end{array}$ \\
\hline Patients: & & \\
F/64 y & 9492 & 20072 \\
M/30 y & 11708 & 42492 \\
F/52 y & 10491 & 43908 \\
Controls: & 10120 & $30072(\mathrm{SD} 1974)^{\star}$ \\
M/28 & 7007 & \\
F/53 & 6751 & \\
M/55 & & \\
\hline
\end{tabular}

${ }^{\star}$ From Llewelyn et al. ${ }^{32}$

Table 3 Sural nerve teased fibre analysis *

\begin{tabular}{lccc}
\hline & \multicolumn{3}{c}{ Case (sex/age) } \\
\cline { 2 - 4 } & $M / 30 y$ & $F / 52 y$ & $F / 64 y$ \\
\hline Normal & 83 & 85 & 76 \\
Degenerating & 0 & 1 & 0 \\
Regenerating & 0 & 0 & 1 \\
Demyelinating & 0 & 0 & 0 \\
Remyelinating & 18 & 15 & 26 \\
\hline
\end{tabular}

^Numbers of fibres for each category.

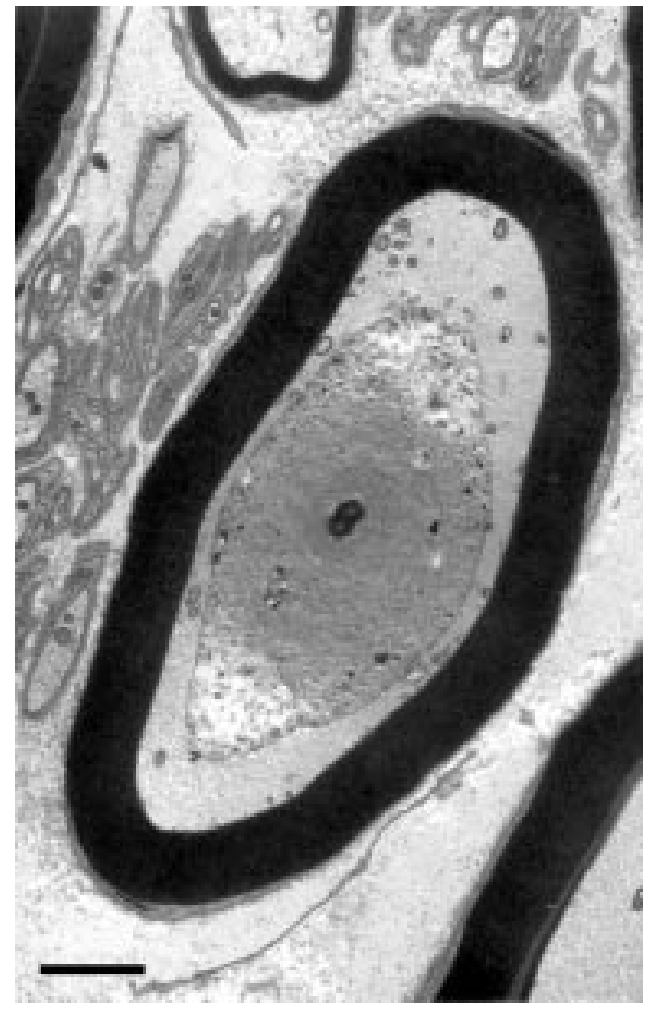

Figure 1 Electron micrograph of transverse section of sural nerve from the 64 year old female patient with CMS showing a myelinated fibre displaying pleomorphic intra-axonal inclusions. Bar $=1 \mu \mathrm{m}$.

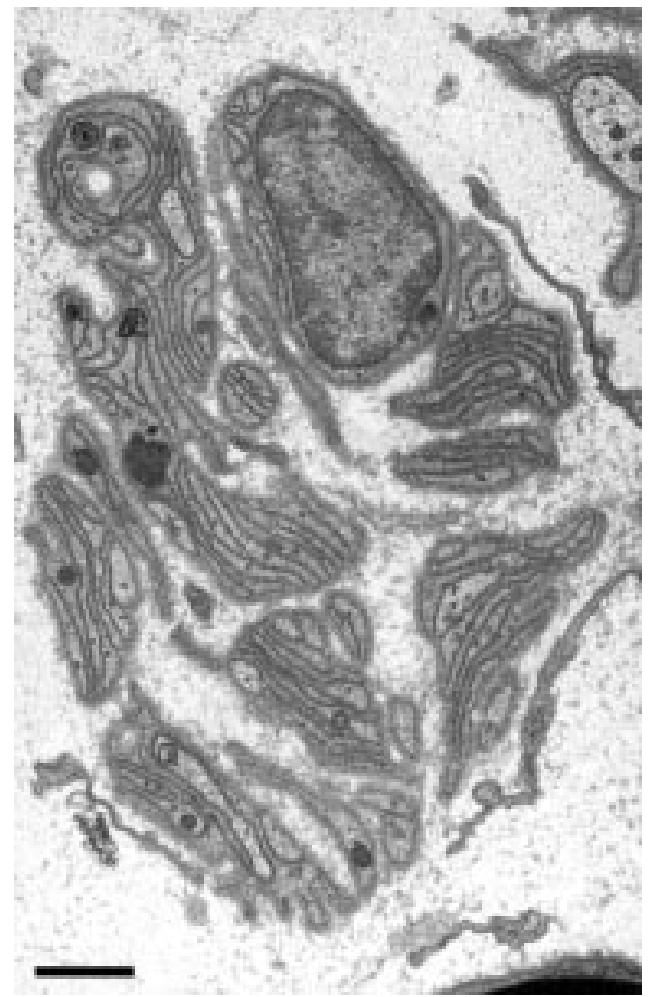

Figure 2 Electron micrograph of transverse section of sural nerve from the 64 year old female patient with CMS showing groups of flattened Schwann cell processes of the type associated with loss of unmyelinated axons. Bar=1 $1 \mu \mathrm{m}$. 
microscope. For the examination of teased fibres, about 100 fibres were isolated in Durcupan without accelerator, mounted on glass slides using the method of Spencer and Thomas, ${ }^{13}$ and categorised according to their morphological appearances. Myelinated fibre density and size distributions were obtained using an IBAS 2 image analyser. Estimates of unmyelinated axon densities were made on electron micrograph montages at a magnification of 10000 .

Morphometry of endoneurial microvessels was performed as described by Bradley et al. ${ }^{14}$ The findings were compared with those from sural nerve specimens from three age matched organ donor control cases.

\section{Results}

NEUROLOGICAL FEATURES

The neurological symptoms reported by the 10 patients with CMS and the five control subjects are listed in table 1 . All patients with CMS but only one control reported recurrent headaches. These were described as being throbbing in quality, bifrontal, generalised, or unilateral in distribution, and sometimes associated with nausea, "dizziness", and visual blurring. Teichopsia was not reported. Intermittent nonspecific "dizziness" of a non-rotational character, unassociated with headache, was reported by five of the patients with CMS but none of the control group. Neither group admitted to ataxia as a symptom.

Intermittent burning and tingling paraesthesiae in the feet and lower legs were experienced by all 10 patients with CMS. The hands were

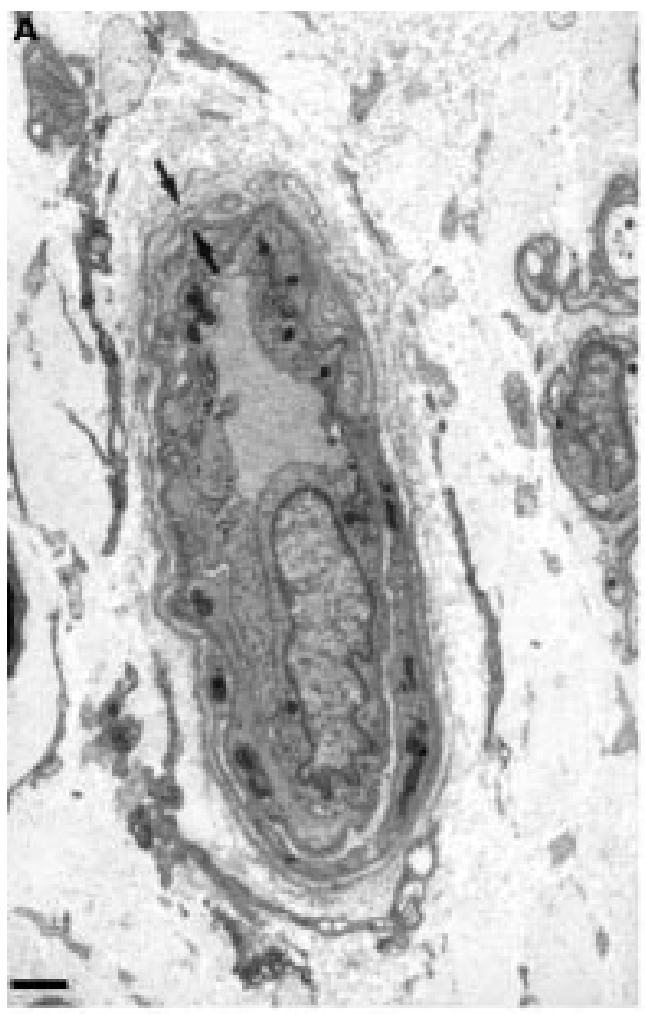

also affected in nine. Of the five control subjects, four complained of intermittent burning paraesthesiae in the feet of lesser severity which had not affected the hands.

An enquiry was made by one of us (JG) as to the effect on the burning paraesthesiae of moving to a lower altitude. Eight patients with this symptom were able to supply information on the influence of moving to sea level at Lima and returning to high altitude at Cerro de Pasco. On transfer to sea level, seven out of eight reported disappearance of the sensory symptoms in the hands before those in their feet, the time for them to resolve in the feet being up to 2 weeks and between 1 and 7 days in the hands. On returning home to high altitude, six out of eight reported a reappearance of the symptoms in the hands before their feet.

The findings on neurological examination are also recorded in table 1 . Muscle wasting or weakness were not detected in any of the subjects, but three patients with CMS showed tendon reflex depression or loss together with mild distal sensory impairment. This affected pain and temperature sensation in all three and also light touch in one. Mild cutaneous hyperaesthesia (allodynia) was evident in one of these patients and also in five others without signs of neuropathy on examination.

NERVE BIOPSY FINDINGS

Examination of semithin transverse sections showed a normal myelinated fibre density that was confirmed by morphometric assessment (table 2). A normal bimodal distribution was present in the patients with CMS. Some fibres

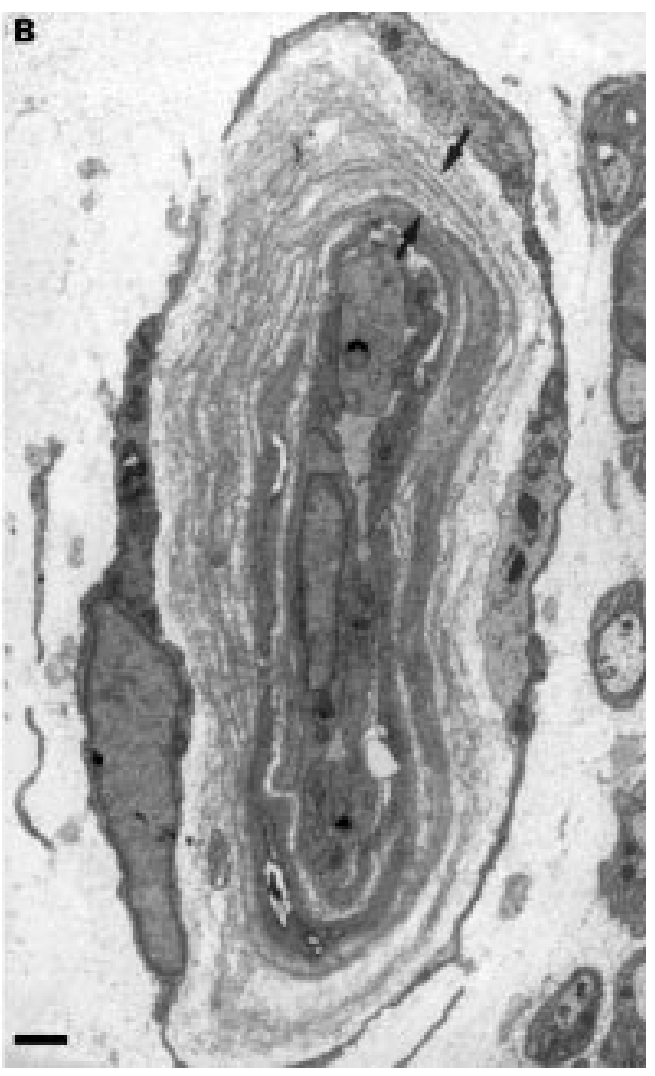

Figure 3 Electron micrograph of a typical endoneurial microvessel from $(A)$ a 64 year old female patient with CMS compared with $(B)$ one from a normal subject aged 55 years in which the surrounding basal laminal zone (between arrows) is thicker. Bar $=1 \mu \mathrm{m}$. 
showed an inappropriately thin myelin sheath for axon diameter. As regenerative clusters were not found, this would suggest remyelination after demyelination. No active fibre degeneration or demyelination was seen in the semithin sections.

The results of the teased fibre analysis are given in table 3 . In all three patients with CMS there was an increased proportion $(18,15$, $25 \%$ ) of fibres showing remyelination. The proportion of fibres showing demyelination and remyelination in control subjects below the age of 45 years is $4 \%{ }^{15}$ but this rises in older people. There was a very low level of fibre degeneration or regeneration.

On electron microscopy occasional fibres undergoing active axonal degeneration were seen and abnormal axonal inclusions including glycogenosomes, polyglucosan bodies, and pleomorphic inclusions were seen (fig 1). Unmyelinated fibres were of normal morphology but their density was moderately reduced in the oldest subject (table 2) and there were sheets of flattened Schwann cells processes of the type associated with loss of unmyelinated axons (fig 2).

The connective tissues showed no abnormality and, in particular, there was no indication of endoneurial oedema or ultrastructural abnormality in the perineurium. The blood vessels showed no pathological features. On morphometric assessment the mean (SEM) density of endoneurial microvessels did not differ from that in the three age matched control nerves (49.68 (21.85) v 48.70 (12.58) $\mathrm{mm}$ respectively;). Their diameter was slightly smaller
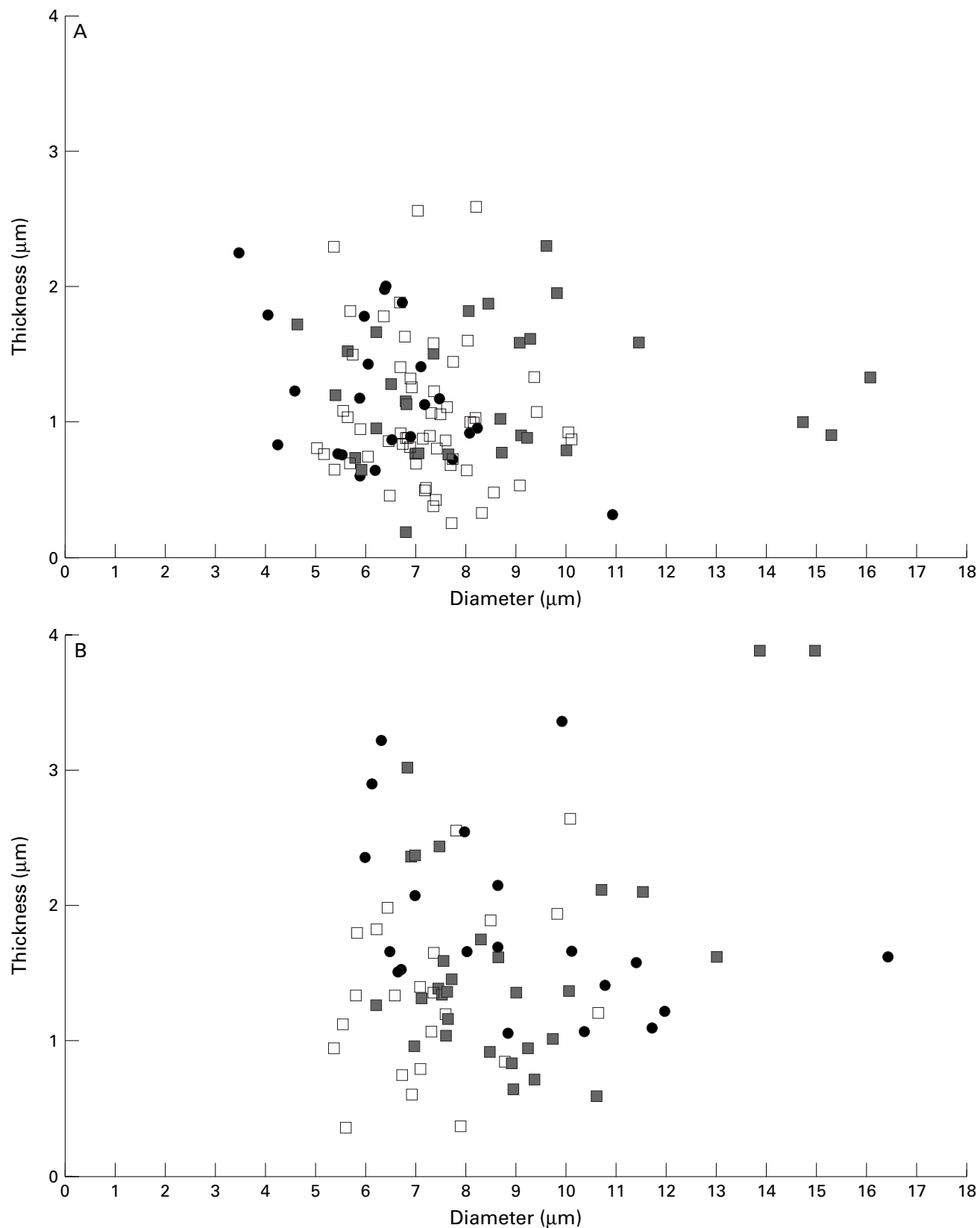

Figure 4 Scatter plots for relation between the thickness of the basal laminal layer and vessel diameter for endoneurial microvessels for the three patients with CMS (A) and the three age matched control subjects (B) A relative lack of thicker basal laminal zones is evident for the patients with CMS. 
(7.37 (0.35) v $8.46(0.32) \mu \mathrm{m})$ but endothelial cell thickness was similar $(2.05(0.13)$ v 2.65 $(0.18) \mu \mathrm{m})$. The mean thickness of the basal laminal zone was less in the three patients with CMS than in the control subjects, being 1.13 (0.04) $\mu \mathrm{m}$ in the first and $1.67(0.11) \mu \mathrm{m}$ in the second (figs $3 \mathrm{~A}$ and $\mathrm{B}$, and $4 \mathrm{~A}$ and $\mathrm{B}$ ).

\section{Discussion}

Burning paraesthesiae may be a troublesome symptom in several peripheral neuropathies. They are prominent in Strachan's syndrome, ${ }^{16}$ a condition originally found in the West Indies ${ }^{17}$ but which has subsequently been encountered under conditions of nutritional deprivation such as during the Spanish Civil War, ${ }^{18}$ in Japanese prisoner of war camps during the second world war ${ }^{19}$ and, most recently, in the epidemic of Cuban neuropathy that occurred in 1991-3. ${ }^{20}$ The precise nature of the nutritional deficiency in Strachan's syndrome has not been identified. None of our patients with CMS showed evidence of nutritional deficiency or alcoholism. Burning feet may occur in diabetic sensory polyneuropathy, particularly in the syndrome of acute painful diabetic sensory neuropathy ${ }^{21}$ when it is associated with severe contact hyperaesthesia of the skin. Diabetes was excluded in our patients.

Burning and tingling paraesthesiae distally in the lower limbs initially suggested the presence of a small fibre neuropathy and these symptoms were reported by all our patients with CMS and in all except one in the hands. This symptom was not restricted to the patients with CMS, however, being reported, in lesser degree and confined to the feet, in four out of five control subjects. There was evidence on neurological examination of a mild distal sensory polyneuropathy in three patients with CMS that predominantly affected small fibre modalities. The biopsy findings indicated the presence of a modest demyelinating neuropathy without a reduction in total myelinated fibre density and a reduced unmyelinated axon density in one biopsy. This altitude associated neuropathy is most probably hypoxic in origin.

The first description of hypoxic neuropathy was given by Appenzeller et al in $1968,{ }^{22}$ who reported a mild distal polyneuropathy in seven out of eight patients with severe chronic obstructive airways disease (COAD). Subsequently Faden et al ${ }^{23}$ documented the presence of mild sensory loss and reflex depression in the legs in four out of 23 patients with chronic respiratory insufficiency.

The most detailed description of the underlying neuropathological changes in hypoxic neuropathy has been provided by Malik et al. ${ }^{24}$ Nerve biopsies obtained from six patients with COAD showed the presence of demyelination and remyelination, a reduced density of unmyelinated axons, and an increased thickness of the basal laminal layer around endoneurial capillaries. The findings in our patients with CMS conform to this apart from the lack of basal laminal thickening. It is of relevance that experimental hypoxia seems to have a selective effect on myelination in peripheral nerve. Benstead et al found that in rats reared under hypoxic conditions there is a selective maldevelopment of peripheral myelin, the myelin sheath being abnormally thin for axon diameter. ${ }^{25}$

Basal laminal thickening around endoneurial microvessels is seen in many neuropathies but is most characteristic of diabetic neuropathy. ${ }^{26}{ }^{27}$ The finding of reduced basal laminal thickness in our patients with CMS is unexpected but not surprising. One possibility is that it is not part of a neuropathic process but represents an adaptive phenomenon to life at high altitude. Similar adaptive microvascular changes have previously been found in other tissues of high altitude native human beings and animals. ${ }^{28}$ It is not unreasonable that the finding of reduced basal laminal thickness in altitude associated hypoxia of nerves differs from that occurring in acquired disease associated hypoxic neuropathies such as that in COAD examined by Malik et al. ${ }^{24}$ Whereas thickening of the basal lamina layer is a non-specific finding in various diseases of peripheral nerves, thinness of this structure, on the other hand, is likely to be a lifelong adaptive process that has now also been found to occur in the human sural nerve.

The relevance of the mild sensory neuropathy in patients with CMS to the occurrence of the burning feet-burning hands syndrome is questionable as patients with neuropathy related to COAD do not experience this symptom, ${ }^{22}{ }^{24}$ and there was no clinical evidence of neuropathy in seven out of our 10 patients with CMS, all of whom experienced burning feet and burning hands. Some other explanation is therefore necessary. In this connection, the improvement of the burning feet and hands on transfer to a lower altitude is of particular interest. The improvement took place over 2 weeks for the lower limbs and 1 week in the upper limbs. On returning to high altitude, the symptoms recurred in the hands before the feet. This fairly rapid time course suggests that the regression is not related to structural restitution. The time course is also too rapid for it to be due to a reduction in blood viscosity, as normalisation of the packed cell volume is known to take about 2 months. ${ }^{29}$ Conversely, it is not rapid enough for it to be related to a direct effect of transfer to normal ambient oxygen concentrations.

The duration and the pattern of disappearance of the symptoms would be consistent with the resolution of a dysfunction involving a factor delivered to the periphery by fast axonal transport. This has a rate of $400 \mathrm{~mm} / \mathrm{day}^{30}$ One possibility would be delivery of nitric oxide synthase. Nitric oxide has a strong vasodilatory action and its lack at the periphery could lead to reduced vascular perfusion. The effect of hypoxia on nitric oxide synthase gene expression in central and peripheral neurons has been examined in rats by Prabhaker et al. ${ }^{31}$ The expression of neuronal nitric oxide synthase (nNOS) mRNA was found to be increased by 10.4 (SD 1.3 ) \% in the vagal nodose ganglia and by 2.0 (SD 1.4)\% in the cerebellum. No significant effect was detected for endothelial nitric oxide synthase (eNOS). As CMS is a 
neuronal maladaptation syndrome, it is conceivable that the upregulation of the nNOS synthase gene in response to hypoxia fails to occur, resulting in a reduced delivery of nNOS synthase to the periphery. This would be corrected by transfer to the higher atmospheric oxygen concentrations at sea level. The pattern of reappearance of symptoms on return to high altitude from sea level would also be consistent with this interpretation, the recurrence affecting the hands before the feet. This is the opposite of the usual pattern for distal "length related" neuropathy, but would be in accordance with the depletion of a factor delivered by axonal transport. Although this hypothesis for the occurrence of the burning feet-burning hands syndrome in CMS is speculative, observations on $\mathrm{nNOS}$ concentrations in peripheral nerve in patients with CMS with this syndrome would be of interest.

The research was funded by NMHEMC Research Foundation, Albuquerque, NM, USA and carried out at the Instituto de Investigationes de Altura, Universidad Peruana Cayetano Heredia, Cerro de Pasco, Peru. We are grateful to our subjects for their cooperation at very short notice and their patience with our curiosity.

1 Arias-Stella J. Chronic mountain sickness: pathology and definition. In: Porter R, Knight J, eds. High altitude physiology: cardiac and respiratory aspects. Edinburgh: Churchill Livingstone, 1971:31-40.

2 Kryger MH, Grover MH. Chronic mountain sickness. Seminars in Respiratory Medicine 1983;5:164-169.

3 Monge MC Sobre un caso de enfermedad de Váquez. I ima: Comunicación presentada a la Academia Nacional de Medicine. 1925;1-7.

4 Leon-Velarde F, Arregui A. Desadaptacion a la vida en las grandes alturas. Travaux de l'Institut Français d'Etudes Andigrandes alturas.
nas 1994;85:81.

5 Arregui A, Leon-Velarde F, Cabrera J, et al. Migraine, polycythemia and chronic mountain sickness. Cephalalgia $1994 \cdot 14: 339-41$.

6 Monge CC, Leon-Velarde F, Arregui A. Increasing prevelance in excessive erythrocytosis with age among healthy high altitude miners. $N$ Engl f Med 1989;321:1271.

7 Lefrançois R, Gautier H, Pasquis P. Ventilatory oxygen drive in acute and chronic hypoxia. Respir Physiol 1968;4:21728.

8 Kryger $\mathrm{MH}$, Weil J, Grover $\mathrm{MH}$. Chronic mountain polycythaemia: a disorder of the regulation of breathing during sleep. Chest 1978;73:303-4.

9 Sun S, Oliver-Pickett C, Ping Y, et al. Breathing and brain blood flow during sleep in patients with chronic mountain sickness. F Appl Physiol 1996;81:611-18.

10 Thomas PK, Muddle JR, King RHM, et al. Neurological manifestations in chronic mountain sickness. Neurology 1998;50:A345

11 Baur PS, Stacey TR. The use of PIPES buffer in the fixation of mammalian and marine tissues for electron microscopy. f Microsc 1977;109:315-27.
12 Sievers J. Basic two-dye stains for epoxy-embedded 0.3-1 um sections. Stain Technology 1971;46:195-99.

13 Spencer PS, Thomas PK. The examination of isolated nerve fibres by light and electron microscopy, with observations on demyelination proximal to neuromas. Acta Neuropathol 1970;16:177-86.

14 Bradley J, Thomas PK, King RHM, et al. Morphometry of endoneurial capillaries in diabetic sensory and autonomic neuropathy. Diabetologia 1990;33:611-18.

15 Dyck PJ, Giannini C, Lais A. Pathologic alterations in nerves. In: Dyck PJ, Thomas PK, Griffin JW, eds. Peripheral neuropathy. Philadelphia: WB Saunders, 1993:514-95.

16 Victor M. Polyneuropathy due to nutritional deficiency and alcoholism. In: Dyck PJ, Thomas PK, Lambert EH, eds. Peripheral neuropathy. Philadelphia: WB Saunders, 1984: 1899-940.

17 Strachan, H. On a form of multiple neuritis prevalent in the West Indies. Practitioner 1897;59:477-84.

18 Peraita M. Deficiency neuropathies observed in Madrid during the civil war (1936-9). BMf 1946;2:784.

19 Cruickshank EK. Painful feet in prisoners-of-war in the far east: review of 500 cases i. Lancet 1946;ii:369-72.

20 Thomas PK, Plant GT, Baxter P, et al. An epidemic of optic neuropathy and painful sensory neuropathy in Cuba: clinical aspects. 7 Neurol 1995;242:629-38.

21 Archer AG, Watkins PJ, Thomas PK, et al. The natural history of acute painful neuropathy in diabetes mellitus. $\mathcal{F}$ Neurol Neurosurg Psychiatry 1983;46:491-9.

22 Appenzeller O, Parks RD, MacGee J. Peripheral neuropathy in chronic disease of the respiratory tract. Am f Med 1968; 44:873-80.

23 Faden A, Mendoza E, Flynn F. Sub-clinical neuropathy associated with chronic obstructive pulmonary disease: possible pathophysiological role of smoking. Arch Neurol 1981;38:639-51.

24 Malik RA, Masson EA, Sharma AK, et al. Hypoxic neuropathy: relevance to human diabetic neuropathy. Diabetologia 1990;33:311-18.

25 Benstead TJ, Dyck PJ, Low P. Chronic hypoxia induces selective maldevelopment of peripheral myelin in rat. $\mathcal{F}$ Neuropathol Exp Neurol 1988;47:599-608.

26 Giannini C, Dyck PJ. Basement membrane reduplication and pericyte degeneration precede development of diabetic polyneuropathy and are associated with its severity. Ann Neurol 1995;37:498-504.

27 Vital C, LeBlanc AC, Vallat JM, et al. Étude ultrastructurale du nerf périphérique chez 16 diabétiques sans neuropathie clinique. Comparaisons avec 16 neuropathies diabétiques et 16 neuropathies non diabétiques. Acta Neuropathol 1974;30:63-72.

28 Heath D, Williams D. Pulmonary vascular remodelling at high altitude. Fournal of Wilderness Medicine 1992;3:15161

29 Peñaloza D, Sime F, Ruiz L. Cor pulmonale in chronic mountain sickness: present concept of Monge's disease. In: Porter R, Knight J, eds. High altitude physiology: cardiac and respiratory aspects. Edinburgh: Churchill Livingstone, 1971: 41-60.

30 Ochs S, Brimijoin WS. Axonal transport. In: Dyck PJ, Thomas PK, Griffin JW, eds. Peripheral neuropathy. Philadelphia: WB Saunders, 1993:331-60.

31 Prabhakar NR, Pieramici SF, Premkumar DR, et al. Activation of nitric oxide synthase gene expression by hypoxia in central and peripheral neurons. Brain Res Mol Brain Res 1996;43:341-6.

32 Llewelyn JG, Gilbey SG, Thomas PK, et al. Sural nerve morphometry in diabetic autonomic and painful sensory neuropathy. Brain 1991;114:867-92. 